(D)

tostates

Cite as

Nano-Micro Lett.

(2020) 12:168

Received: 26 May 2020

Accepted: 22 July 2020

Published online: 18 August 2020

(C) The Author(s) 2020

\section{Niobium Tungsten Oxide in a Green Water-in-Salt Electrolyte Enables Ultra-Stable Aqueous Lithium-Ion Capacitors}

\author{
Shengyang Dong ${ }^{1,2}$, Yi Wang ${ }^{3}$, Chenglong Chen ${ }^{2}$, Laifa Shen ${ }^{2}$, Xiaogang Zhang ${ }^{2} \bowtie$ \\ $\triangle$ Laifa Shen, lfshen@nuaa.edu.cn; Xiaogang Zhang, azhangxg@nuaa.edu.cn \\ 1 School of Chemistry and Materials Science, Institute of Advanced Materials and Flexible \\ Electronics (IAMFE), Nanjing University of Information Science and Technology, Nanjing 210044, \\ People's Republic of China \\ 2 Jiangsu Key Laboratory of Electrochemical Energy Storage Technologies, College of Materials \\ Science and Technology, Nanjing University of Aeronautics and Astronautics, Nanjing 210016, \\ People's Republic of China \\ 3 Max Planck Institute for Solid State Research, Heisenbergstrasse 1, 70569 Stuttgart, Germany
}

\title{
HIGHLIGHTS
}

- A green water-in-salt electrolyte was developed using lithium acetate as solute with a wide electrochemical stability window of $2.8 \mathrm{~V}$.

- Molecular dynamics simulation confirmed the nature of water-in-salt electrolyte, where hydrogen bonds of water-water were disrupted and ionic interactions became stronger than dilute solution.

- $\mathrm{Nb}_{18} \mathrm{~W}_{16} \mathrm{O}_{93}$-based lithium-ion capacitors delivered unexceptionable stability over 50,000 cycles.

\begin{abstract}
Aqueous hybrid supercapacitors are attracting increasing attention due to their potential low cost, high safety and eco-friendliness. However, the narrow operating potential window of aqueous electrolyte and the lack of suitable negative electrode materials seriously hinder its future applications. Here, we explore high concentrated lithium acetate with high ionic conductivity of $65.5 \mathrm{mS} \mathrm{cm}^{-1}$ as a green "water-in-salt" electrolyte, providing wide voltage window up to $2.8 \mathrm{~V}$. It facilitates the reversible function of niobium tungsten oxide, $\mathrm{Nb}_{18} \mathrm{~W}_{16} \mathrm{O}_{93}$, that otherwise only operations in organic electrolytes previously. The $\mathrm{Nb}_{18} \mathrm{~W}_{16} \mathrm{O}_{93}$ with lithium-ion intercalation pseudocapacitive behavior exhibits excellent rate performance, high areal capacity, and ultra-long cycling stability. An aqueous lithium-ion hybrid capacitor is developed by using $\mathrm{Nb}_{18} \mathrm{~W}_{16} \mathrm{O}_{93}$ as negative electrode combined with graphene as positive electrode in lithium acetate-based "water-in-salt" electrolyte, delivering a high energy density of $41.9 \mathrm{~W} \mathrm{~kg}^{-1}$, high power density of $20,000 \mathrm{~W} \mathrm{~kg}^{-1}$ and unexceptionable stability of 50,000 cycles.
\end{abstract}

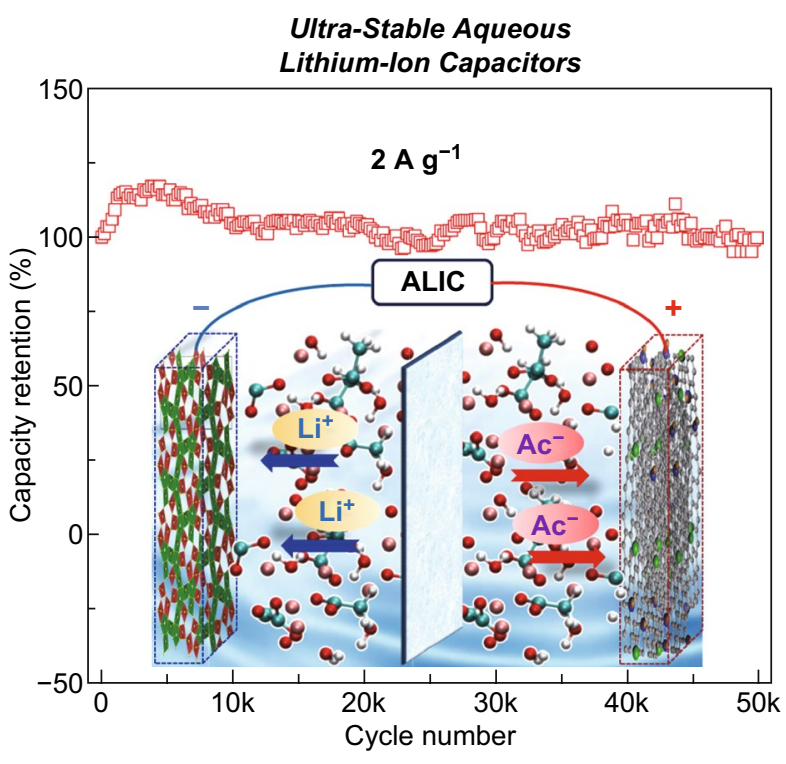

KEYWORDS Aqueous hybrid capacitors; Water-in-salt electrolyte; Niobium tungsten oxide; Ultra-stability; High power density 


\section{Introduction}

There exist tremendous needs for grid storage to couple the renewable-but-intermittent solar and wind energy [1-3]. Electrochemical energy storage is promising, because it provides a modular solution, which is less geographically restricted than pumped hydro- and compressed air storage, etc. [4-6]. The metric to evaluate energy storage is the levelized cost and the life time of the devices. To minimize such cost, one should use aqueous electrolytes to lower the acquisition cost and maximize the cycle life so that maintenance cost can be low [7-10]. Besides, compared with organic cells, aqueous electrolytes are noninflammable and eco-friendly. Therefore, it is strategically advantageous to employ electrochemical devices with aqueous electrolytes for large-scale energy storage.

Among the aqueous energy storage technologies, there are electrochemical capacitors (ECs) and rechargeable batteries, etc. The advantages of ECs are the ultra-long cycle life and the high power performance [11, 12]. However, ECs suffer from low energy density, usually less than $10 \mathrm{Wh} \mathrm{kg}^{-1}$, and their self-discharge is quite severe, particular for the aqueous ECs [13]. Rechargeable batteries, especially lithium-ion batteries (LIBs), provide high energy density $[14,15]$. But the power character and cycling lifespan are unacceptable [16, 17]. There are also hybrid energy storage devices, for example, lithium-ion hybrid capacitors (LICs), where one electrode operates on Faradaic reactions, and the other uses electrical double layer (EDL) storage [18-20]. For example, during charge, the positive electrode incorporates anions adsorption and the negative electrode takes in cations in reductive ion insertion; during discharge, the ion migration direction is reversed. The trade-off between ECs and LIBs of LICs recently received much attention due to their excellent energy-power characters and long lifespan [21-23]. However, the state-of-the-art aqueous lithium-ion hybrid capacitors (ALICs) have been limited with their narrow electrochemical stability window of the water $(\sim 1.23 \mathrm{~V})$ and sluggish diffusion in the bulk of battery-type materials.

Fortunately, "water-in-salt" electrolytes (WiSEs) are effective strategies to extend the electrochemical stability window of aqueous electrolytes [24-28]. This approach was first reported by Suo et al. using $21 \mathrm{~m}$ lithium bis(trifluoromethanesulfonyl) (LiTFSI) [24]. Albeit with the attractive performance achieved, the majority of previous reports make use of highly concentrated fluorinated salt (such as LiTFSI, $\left.\operatorname{LiN}\left(\mathrm{SO}_{2} \mathrm{C}_{2} \mathrm{~F}_{5}\right)_{2}\right)$ [25], which are notoriously wasteful. This goes against the original aims of aqueous cells, which are environmental friendliness and low cost. Recently, fluorine-free WiSEs received much attention due to their green and low-cost. Among them acetate (Ac)-based WiSEs are the famous alternatives, including potassium acetate (KAc) [29], KAc + lithium acetate $(\mathrm{LiAc})$ [9], $\mathrm{KAc}+$ sodium acetate $(\mathrm{NaAc})$ [30], and ammonium acetate (AmAc) [31], etc.

Another main challenge of ALICs is how to promote the quick-charge characteristic and high stability of battery-type materials. Recently, Grey et al. reported a niobium tungsten oxide $-\mathrm{Nb}_{18} \mathrm{~W}_{16} \mathrm{O}_{93}$ (NbWO), which adopt bronze-like structure with high lithium-ion diffusion coefficient in the order of $10^{-13} \mathrm{~m}^{2} \mathrm{~s}^{-1}$ [32]. This material possesses high rate characteristic and cycle stability even the particle size is of the order of micrometers. However, the high potential of lithium-ion intercalation is not very ideal as a negative electrode material in organic cells.

Herein, we demonstrate the efficacy of high concentrated lithium acetate as a green, fluorine-free "water-insalt" electrolyte with low viscosity, high ionic conductivity, and wide voltage window up to $2.8 \mathrm{~V}$. The molecular dynamics (MD) simulation disclose that the interaction between $\mathrm{H}_{2} \mathrm{O}$ and $\mathrm{Ac}^{-}$arises in the concentrated electrolyte to break the ubiquitous hydrogen bonding network between $\mathrm{H}_{2} \mathrm{O}$ molecules, which is mainly responsible for the expanded electrochemical stability window. Furthermore, a novel ALIC is developed, which employs $\mathrm{Nb}_{18} \mathrm{~W}_{16} \mathrm{O}_{93}$ (NbWO) as a negative electrode and a positive electrode of oxygen-enriched crumpled graphene (OECG) in LiAc-based WiSE with high energy-power density and unexceptionable stability of 50,000 cycles.

\section{Experimental Section}

\subsection{Preparation of $\mathrm{Nb}_{18} \mathrm{~W}_{16} \mathrm{O9}_{3}$}

$\mathrm{Nb}_{18} \mathrm{~W}_{16} \mathrm{O}_{93}$ was prepared by a simple solid state reaction established in Grey's previous work [32] with a minor modification. Typically, $\mathrm{Nb}_{2} \mathrm{O}_{5}$ and $\mathrm{WO}_{3}$ powers $(\mathrm{Nb}: \mathrm{W}=9: 8 \mathrm{in} \mathrm{mol} / \mathrm{mol}$ ) were used as the raw materials to 
synthesize $\mathrm{Nb}_{18} \mathrm{~W}_{16} \mathrm{O}_{93}$ ( $\mathrm{NbWO}$ ). After thoroughly grinding in an agate mortar with moderate absolute ethanol, the resulting mixture was pressed into pellets at a pressure of $10 \mathrm{MPa}$ and then annealing in a Pt crucible covered with a Pt lid at $700{ }^{\circ} \mathrm{C}$ for $12 \mathrm{~h}$ with a heating rate of $10{ }^{\circ} \mathrm{C} \mathrm{min}{ }^{-1}$ followed by $1200{ }^{\circ} \mathrm{C}$ for $12 \mathrm{~h}$ with a heating rate of $5^{\circ} \mathrm{C}$ $\min ^{-1}$ in air atmosphere.

\subsection{Materials Characterization, Electrochemical Measurement and Molecular Dynamics Simulation}

Detailed information about the materials characterization, electrochemical measurement, and molecular dynamics (MD) simulations are provided in the Supporting Information.

\section{Results and Discussion}

\subsection{Characterization of Water-in-Salt Electrolyte}

Concentrated LiAc solutions achieve molalities up to $13 \mathrm{~m}$, corresponding to about $4 \mathrm{H}_{2} \mathrm{O}$ molecules per $\mathrm{Li}^{+}$. Molecular dynamics (MD) simulations were first performed to study the variations of the spatial micro-configurations of aqueous LiAc electrolyte system (Table S1). Figure 1a, b exhibit the snapshot of microstructure for 1 and $13 \mathrm{~m} \mathrm{LiAc}$ solution. It can be found that, in $1 \mathrm{~m} \mathrm{LiAc}$, the $\mathrm{Li}^{+}$freely coordinated with $\mathrm{H}_{2} \mathrm{O}$ molecules (Fig. 1c). The hydrogen bond is the main interaction in this dilute solution. However, in $13 \mathrm{~m} \mathrm{LiAc}, \mathrm{Ac}^{-}, \mathrm{Li}^{+}$, and $\mathrm{H}_{2} \mathrm{O}$ molecules are complete mixed together (Fig. 1d). The $\mathrm{H}_{2} \mathrm{O}$ molecules mainly interact with the nearby $\mathrm{Li}^{+}$and $\mathrm{Ac}^{-}$, and the hydrogen bonds almost disappear. This will greatly affect the physical and chemical properties, such as density, viscosity, conductivity, thermostability, and electrochemical stability window [33]. As shown in the radial distribution function (RDF) curves (Fig. 1e, f), the distance between $\mathrm{Ow}(\mathrm{O}$ atom in $\left.\mathrm{H}_{2} \mathrm{O}\right)$ and $\mathrm{Hc}\left(\mathrm{H}\right.$ atom connected with $\mathrm{C}$ atom in $\mathrm{Ac}^{-}$) shifts from 0.36 (in $1 \mathrm{~m} \mathrm{LiAc}$ ) to $0.35 \mathrm{~nm}$ (in $13 \mathrm{~m} \mathrm{LiAc}$ ). This may be caused by the fact that the interaction between $\mathrm{H}_{2} \mathrm{O}$ molecules and $\mathrm{Ac}^{-}$becomes stronger in the concentrated electrolyte. Besides, the peaks of $\mathrm{Oc}-\mathrm{Hw}$ and $\mathrm{Hc}-\mathrm{Ow}$ become stronger in the concentrated solution. This means that $\mathrm{Ac}^{-}$tends to interact with the $\mathrm{H}_{2} \mathrm{O}$ molecules when the number of $\mathrm{Ac}^{-}$increases. Table $\mathrm{S} 2$ summarizes the physical properties of 1 and $13 \mathrm{~m} \mathrm{LiAc}$ electrolytes. MD predicted the densities of 1 and $13 \mathrm{~m} \mathrm{LiAc}$ are 0.99 and $1.18 \mathrm{~g} \mathrm{~cm}^{-3}$, respectively. The viscosity of concentrated electrolyte is only $9.5 \mathrm{mPa}$ s at $25{ }^{\circ} \mathrm{C}$, which value is superior to the most previously reported WiSEs and organic electrolytes [9, 25, 34, 35].

The electrochemical stability window of LiAc-based electrolytes was evaluated via cyclic voltammetry $(\mathrm{CV})$ at a scan rate of $10 \mathrm{mV} \mathrm{s}^{-1}$. As shown in Fig. 1g, it demonstrates that the $13 \mathrm{~m} \mathrm{LiAc}$ delivers a wide electrochemical window of about $2.8 \mathrm{~V}$ using cutoff current density of $50 \mu \mathrm{A} \mathrm{cm} \mathrm{cm}^{-2}$, from -1.3 to $1.5 \mathrm{~V}$ (vs. $\mathrm{Ag} / \mathrm{AgCl}$ ). However, as for $1 \mathrm{~m}$ LiAc electrolyte, the stability window is only about $1.8 \mathrm{~V}$. The thermogravimetric/differential scanning calorimetry (TG/DSC) data (Fig. 1h) also demonstrate that $13 \mathrm{~m} \mathrm{LiAc}$ electrolyte has a much better thermostability than water. As shown in Fig. 1i, the LiAc electrolytes possess high conductivity of $65.5 \mathrm{mS} \mathrm{cm}{ }^{-1}$ even at high molality of $13 \mathrm{~mol} \mathrm{~kg}^{-1}$, which exceeds that of the LiTFSI-based and hydrate-melt electrolytes at the comparable concentrations [24, 25].

\subsection{Characterization of Niobium Tungsten Oxide}

The as-prepared $\mathrm{Nb}_{18} \mathrm{~W}_{16} \mathrm{O}_{93}$ were first characterized by X-ray diffraction (XRD) to determine its crystallographic structure. As can be seen in Fig. 2a, all of the diffraction peaks can be well indexed to the orthorhombic tetragonal tungsten bronze (JCPDS No 75-0561) [32, 36]. The sharp and well-recognized diffraction peaks demonstrates the high crystallinity arising from the high temperature annealing. As shown in the structural diagram in Fig. 1b, the superstructure of NbWO results from partial filling of pentagonal tunnels by $-\mathrm{M}-\mathrm{O}-$ polyhedrons $(\mathrm{M}=\mathrm{Nb}$ or $\mathrm{W})$ to form pentagonal bi-pyramids, with the distorted octahedra of the tetragonal tungsten bronzes. We further investigated the microstructure of the as-prepared NbWO by scanning electron microscopy (SEM) and highresolution transmission electron microscopy (HRTEM). In the SEM images (Figs. 2c and S1), NbWO shows large block morphology (1-2 $\mu \mathrm{m}$ primary, 10-20 $\mu \mathrm{m}$ agglomerate). Obviously, the crystal lattice fringes with the interplanar distance of $3.95 \AA$ can be observed in Fig. 2d, which is consistent with the interplanar spacing of the (001) plane of NbWO. More important, the atomic structure of $\mathrm{NbWO}$ is revealed by aberrationcorrected scanning transmission electron microscopy (STEM) with high-angle annular dark field (HAADF) detector for the 
(a)

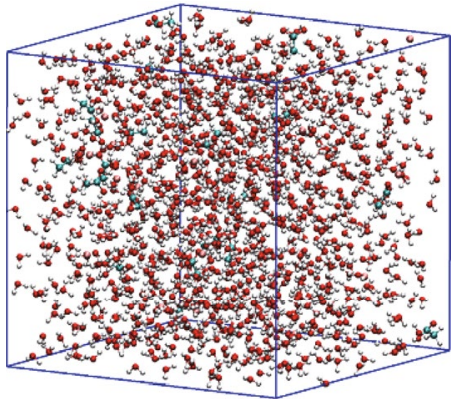

(b)
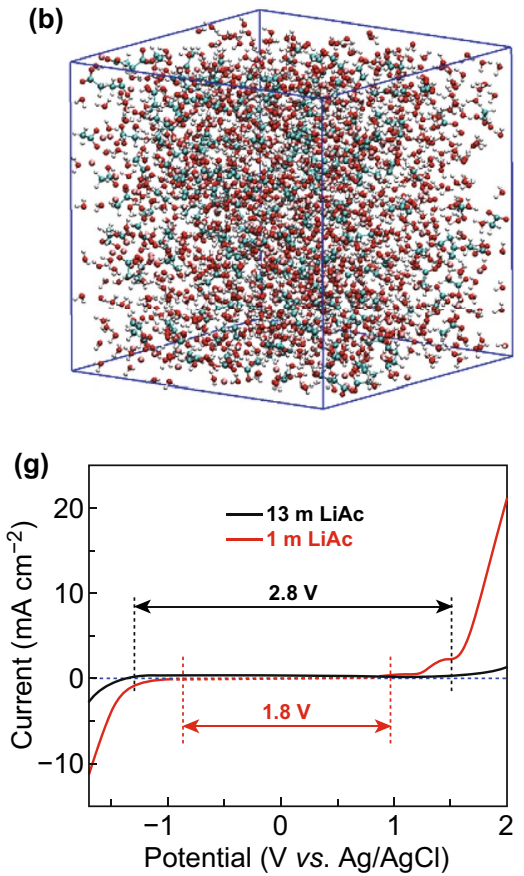

(c)

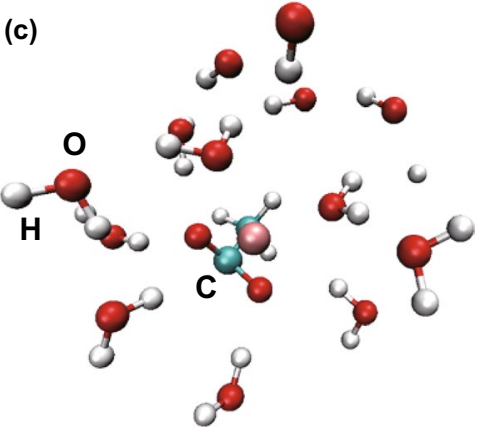

(d)

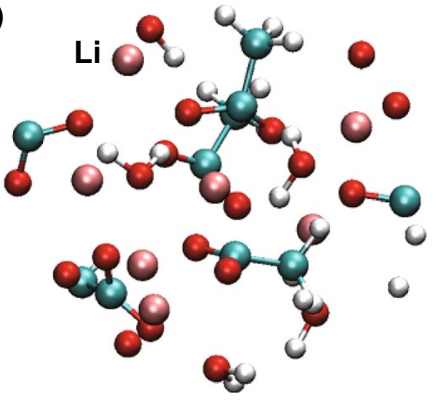

(e)

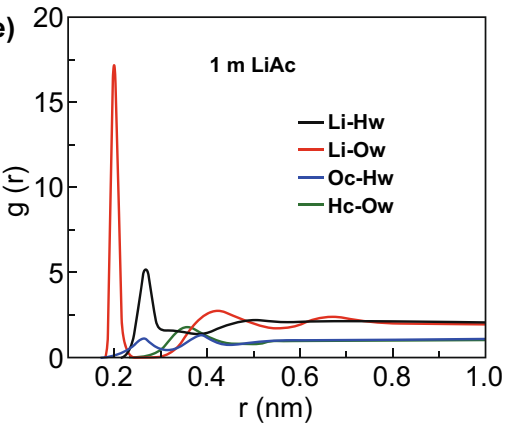

(f)

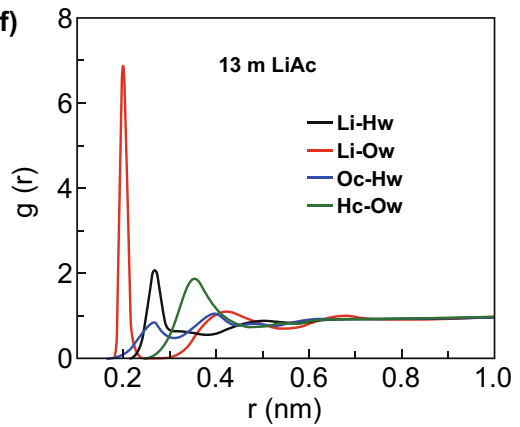

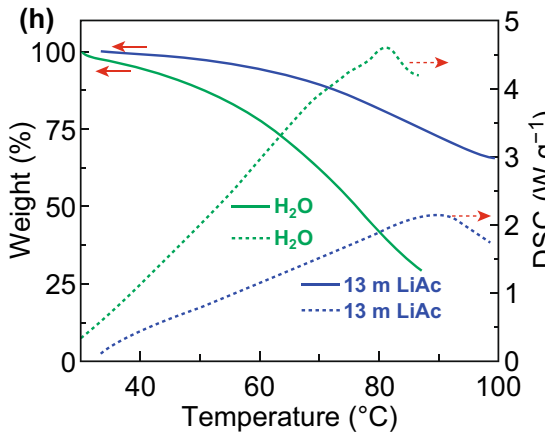

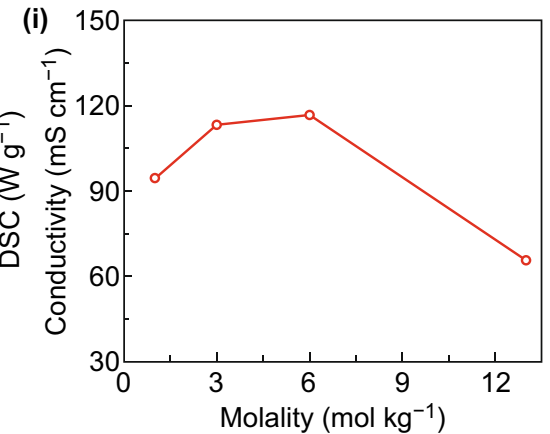

Fig. 1 Physicochemical properties of the LiAc aqueous electrolytes. Snapshots of microstructure for the $1 \mathrm{~m} \mathrm{LiAc}(\mathbf{a}, \mathbf{c})$ and the $13 \mathrm{~m} \mathrm{LiAc}$ electrolyte (b, d) by MD simulations after 4 ns. Atom colors: Li, brown; O, red; H, gray; C, blue. RDF curves of Li-Hw, Li-Ow, Oc-Hw, and $\mathrm{Hc}-\mathrm{Ow}$, respectively, in the $1 \mathrm{~m} \mathrm{LiAc}(\mathbf{e})$ and the $13 \mathrm{~m} \mathrm{LiAc}$ electrolyte (f). $\mathrm{Hw}$ represents $\mathrm{H}$ atom in $\mathrm{H}_{2} \mathrm{O}, \mathrm{Ow}$ represents $\mathrm{O}$ atom in $\mathrm{H}_{2} \mathrm{O}, \mathrm{Oc}$ represents $\mathrm{O}$ atom connected with $\mathrm{C}$ atom in $\mathrm{Ac}^{-}, \mathrm{Hc}$ represents $\mathrm{H}$ atom connected with $\mathrm{C}$ atom in $\mathrm{Ac}^{-}$. g Cyclic voltammetry $(\mathrm{CV})$ curves collected in $1 \mathrm{~m}$ and $13 \mathrm{~m} \mathrm{LiAc}$ at $10 \mathrm{mV} \mathrm{s}^{-1}$. h TG/DSC data of the $\mathrm{H}_{2} \mathrm{O}$ and the $13 \mathrm{~m} \mathrm{LiAc}$ electrolyte. $\mathbf{i}$ The conductivity as a function of their molality values

first time. The corresponding HAADF images are presented in Fig. 2e, f, with the [001] crystallographic direction. Due to the much weaker electron scattering of $\mathrm{O}$ atoms than that of $\mathrm{Nb}$ and $\mathrm{W}$, the $\mathrm{O}$ atoms are invisible in the HAADF image. The atomic arrangement in Fig. $2 \mathrm{f}$ matches well with the inset structure model as shown in Fig. $2 b$.

\subsection{Evaluation of Li-Ion Storage}

Reaction of NbWO with $\mathrm{Li}^{+}$proceeds in the potential window of -1.3 to $0 \mathrm{~V}$ (all potentials of three electrodes hereafter are referred to $\mathrm{Ag} / \mathrm{AgCl})$. Figure 3 a exhibits the typical CV curves of NbWO electrode in 1 and $13 \mathrm{~m} \mathrm{LiAc}$ 

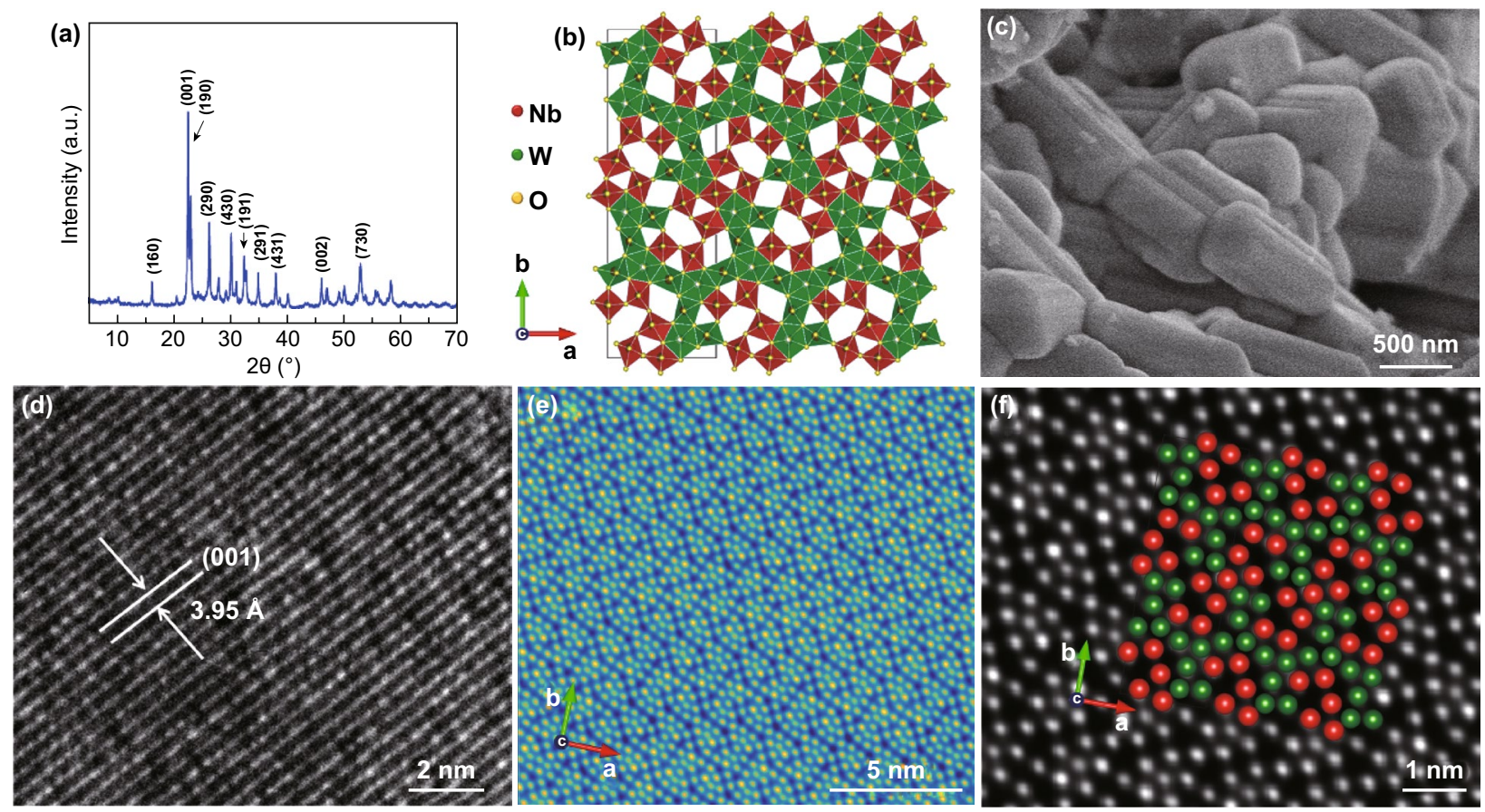

Fig. 2 Microstructural characterizations of NbWO. a XRD pattern. b Structural diagram of NbWO along the $c$ axis. c SEM image. d HR-TEM image. e, f Aberration-corrected HAADF-STEM images of atomic arrangement which match the inset structure model viewed along the [001] crystallographic direction, W:green; $\mathrm{Nb}$ : red
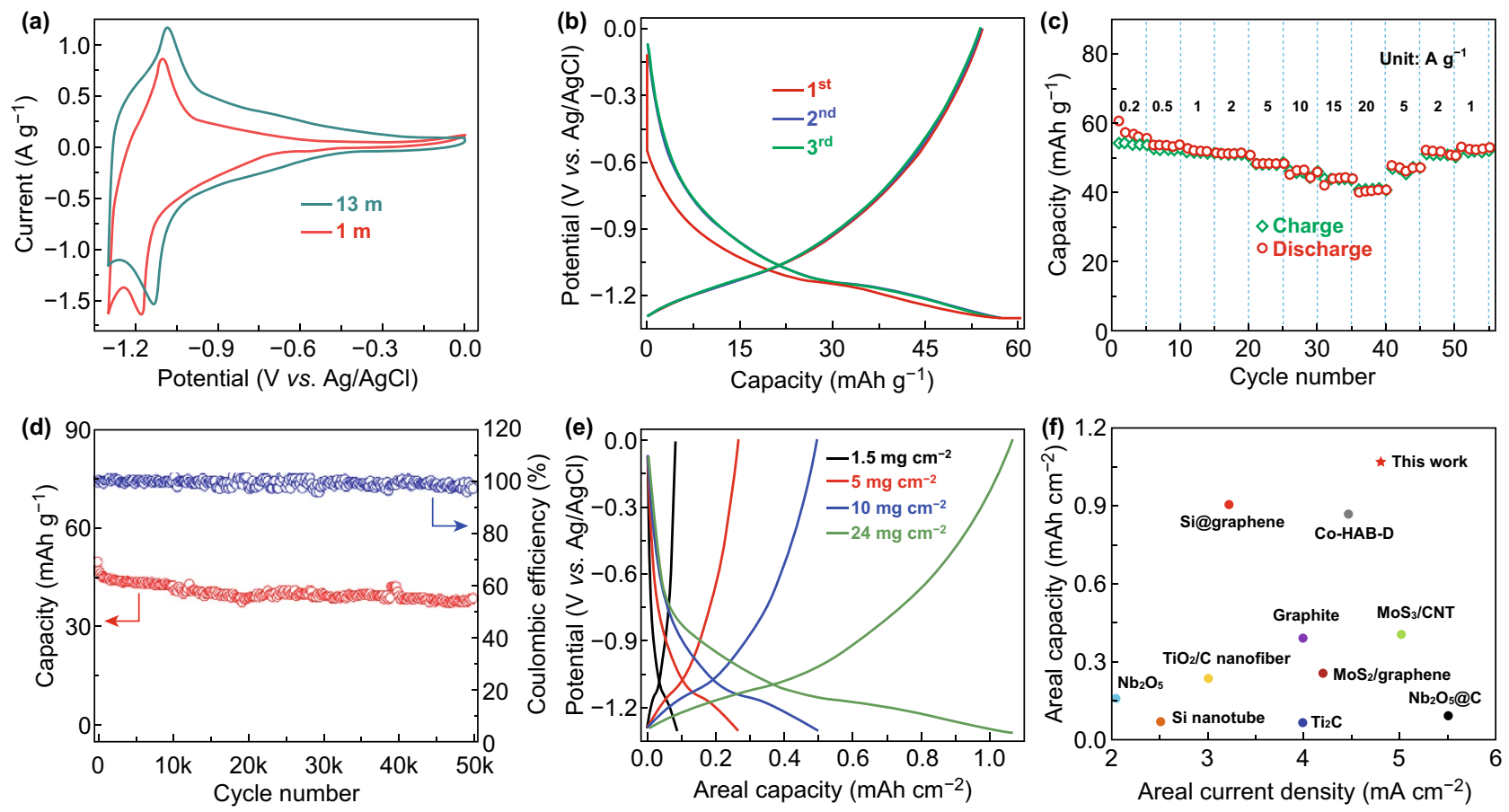

Fig. 3 Lithium-ion storage performance of NbWO electrode. a Typical CV curves in $1 \mathrm{~m}$ and $13 \mathrm{~m} \mathrm{LiAc} \mathrm{electrolytes} \mathrm{at} 2 \mathrm{mV} \mathrm{s}{ }^{-1}$. b GCD curves at $200 \mathrm{~mA} \mathrm{~g}^{-1}$. c Rate performance. d Cycling stability at $2 \mathrm{~A} \mathrm{~g}^{-1}$. e GCD curves with various active mass loadings. $\mathbf{f}$ Areal capacity comparison of the NbWO electrode with representative anode materials for non-aqueous energy storage in previous reports 
electrolytes. Apparently, a big polarization is observed in $1 \mathrm{~m} \mathrm{LiAc}$ solution, which is attributed to the reduction of $\mathrm{H}_{2} \mathrm{O}$ with $\mathrm{H}_{2}$ evolution. On the contrary, a reversible redox pair appears at around $-1.1 \mathrm{~V}$ in $13 \mathrm{~m}$ LiAc solution, which corresponds to the reversible $\mathrm{Li}^{+}$insertion/extraction reaction of NbWO. The small polarization potential of $0.08 \mathrm{~V}$ means superior high rate performance. Figure $3 \mathrm{~b}$ shows the galvanostatic charge-discharge (GCD) curves of the NbWO electrode at $200 \mathrm{~mA} \mathrm{~g}^{-1}$ with a reversible capacity of about $54 \mathrm{mAh} \mathrm{g}^{-1}$ in $13 \mathrm{~m} \mathrm{LiAc}$ electrolyte. However, in $1 \mathrm{~m}$ LiAc electrolyte, as shown in Fig. S2, the NbWO electrode doesn't work at all with the same potential window. When the kinetics was examined over a range of current densities from $200 \mathrm{~mA} \mathrm{~g}^{-1}$ to $15 \mathrm{~A} \mathrm{~g}^{-1}$, NbWO showed superior rate performance (Fig. 3c) in $13 \mathrm{~m} \mathrm{LiAc}$ electrolyte. Even elevate to $20 \mathrm{~A} \mathrm{~g}^{-1}$, the capacity of $\mathrm{NbWO}$ is still remain at about $40 \mathrm{mAh}^{-1}$, equivalent to $74.1 \%$ of the capacity at $200 \mathrm{~mA} \mathrm{~g}^{-1}$. The cycling performance is one of the longest cycling performances for batteries in previous reports. The capacity retention is up to $85.5 \%$ after 50,000 cycles at $2 \mathrm{~A} \mathrm{~g}^{-1}$ (Fig. 3d). In order to increase the areal capacity, we further investigated the electrochemical characteristics of NbWO electrodes with high mass loading from 1.5 to $24 \mathrm{mg} \mathrm{cm}^{-2}$, which is one of the key indicators for practical applications. As shown in Fig. 3e, the areal capacity can be increased almost linearly from 0.08 to $1.09 \mathrm{mAh}$ $\mathrm{cm}^{-2}$. More significantly, $85.2 \%$ of specific capacity of the $1.5 \mathrm{mg} \mathrm{cm}^{-2}$ electrode is still exhibited even in the 16 times thicker electrode $\left(24 \mathrm{mg} \mathrm{cm}^{-2}\right)$, which confirms prominent transport kinetics in the NbWO electrode. We compared the areal performance of $\mathrm{NbWO}$ with other secondary batteries, including LIBs and Na-ion batteries (NIBs) even in organic systems (Fig. 3f). Obviously, among the previous reported graphite [37], Si [38, 39], metal oxides/sulfides/carbides [40-45], even the emerging conductive metal organic framework (MOF) anodes [46], NbWO demonstrated one of the best integrative areal electrochemical character. The impressive electrochemical performance of NbWO may benefit from the rapid electrode kinetics, which is derived from its prop open framework network, and the high-stable LiAc-based WiSE.

We further conducted X-ray photoelectron spectroscopy (XPS) at different states of charge (SOC) to analyze the valence of niobium and tungsten (Fig. S3). As shown in Fig. $\mathrm{S} 3 \mathrm{~b}$, the $\mathrm{Nb} 3 d$ binding energies of $\mathrm{NbWO}$ are located at 210.3 and $207.6 \mathrm{eV}$, confirming $\mathrm{Nb}(\mathrm{V})$; when discharged to $-1.3 \mathrm{~V}$ (all potentials are vs. $\mathrm{Ag} / \mathrm{AgCl}$ ), the two sharp peaks at 209.8 and $207.1 \mathrm{eV}$ are indexed to $\mathrm{Nb}$ (IV) [47]. Upon charging back to $0 \mathrm{~V}$, the $\mathrm{Nb} 3 d$ peaks recovered back to the original binding energies of $\mathrm{Nb}(\mathrm{V})$. Similarly, $\mathrm{W}$ also shows reversible redox based on $\mathrm{W}(\mathrm{VI}) / \mathrm{W}(\mathrm{V})$ during charge/discharge process (Fig. S3c). In addition, with a careful observation, there appears to be a larger shift in the binding energies of W(4f) for the discharged to $-1.0 \mathrm{~V}$, indicating a slight tendency for $\mathrm{W}$ reduction initially. To reveal the impact of the Li-ion storage on the structure of $\mathrm{NbWO}$, we collected ex situ XRD patterns at a selected SOC in the first cycle. As shown in Fig. S4, the main peaks minor shift to lower degree after lithiation. Upon de-lithiation to $0 \mathrm{~V}$, the main peaks return back to their initial positions gradually. It indicates that NbWO has excellent structural stability during the electrochemical process.

Kinetic analysis using CV technology was conducted to acquire further insight into the excellent electrochemical character of NbWO. Figure 4 a displays the typical $\mathrm{CV}$ curves for the NbWO electrode at scan rates from 1 to $5 \mathrm{mV} \mathrm{s}^{-1}$. It is important to highlight that the small potential offsets are nearly constant even the scan rate increases to $5 \mathrm{mV} \mathrm{s}^{-1}$, demonstrating small polarization even at high rates. Indeed, the current in $\mathrm{CV}$ curves can be deconvoluted to two components: the capacitive non-diffusioncontrolled process and the diffusion-controlled process. To shed light on the charge storage kinetics, we analyze the response current $(i)$ by the power-law dependence, $i=a v^{b}$, where $v$ is the scan rate in $\mathrm{CV}$, and $a$ and $b$ are coefficients. Particularly, if the redox reaction is diffusion controlled, $b$ is $0.5 ; b$ is 1.0 when non-diffusion controlled. As shown in Fig. $4 \mathrm{~b}$, all the $b$-values are between 0.75 and 1 , indicating that the current is predominantly capacitive even at redox region.

The kinetics can also be quantified by deconvoluting the current, $i$, at a particular potential $V$ into capacitive $\left(k_{1} v\right)$ and semi-infinite linear diffusion-controlled processes $\left(k_{2} v^{1 / 2}\right)[40]$ :

$i(V)=k_{1} v+k_{2} v^{1 / 2}$

Under this mathematical treatment, the extent of capacitive storage of $\mathrm{NbWO}$ is about $91.2 \%$ at $5 \mathrm{mV} \mathrm{s}^{-1}$ (Fig. $4 \mathrm{c}$ ), which is presented by the red-shaded area. The quantified results (Fig. 4d) show that the capacitive capacity is 

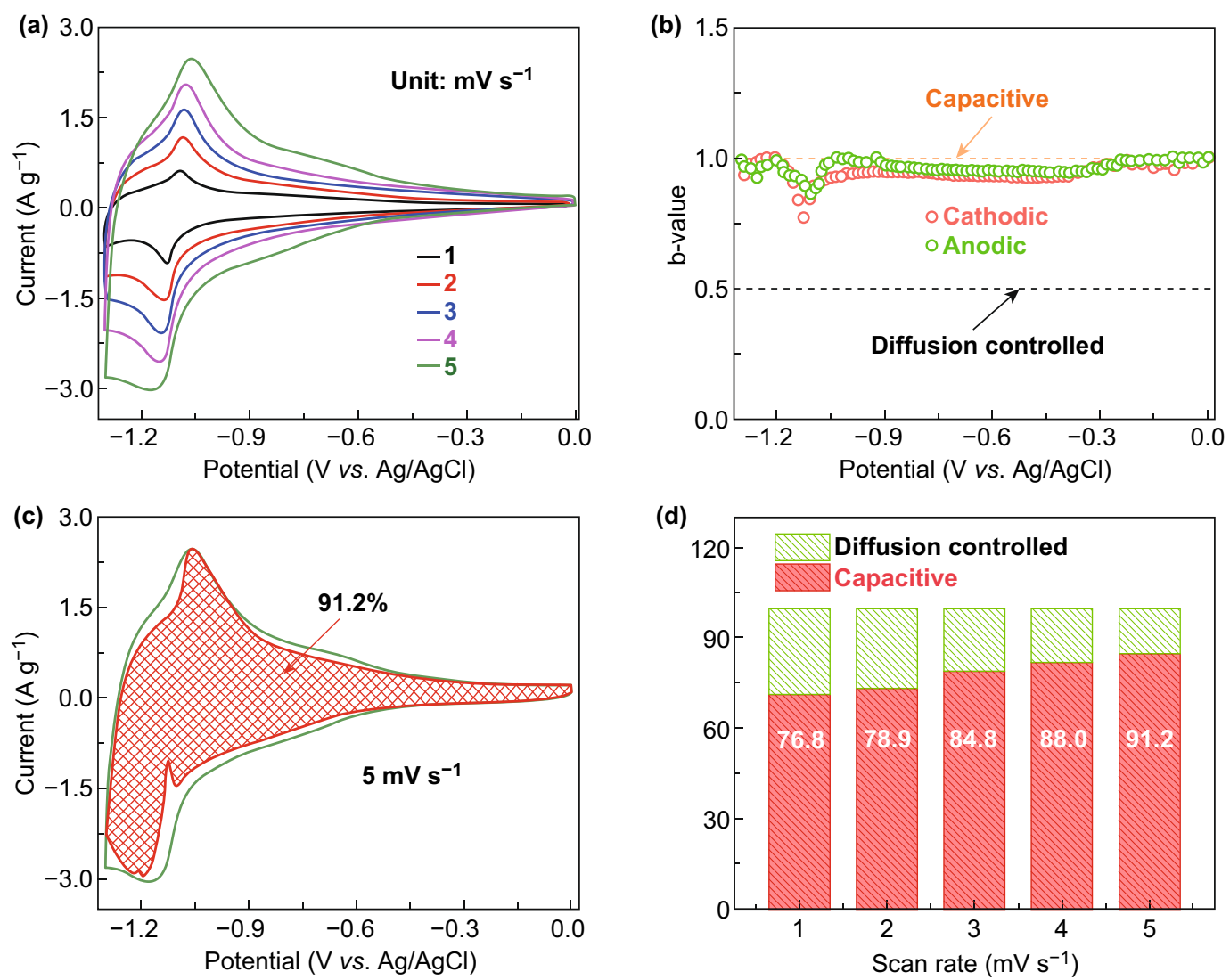

Fig. 4 Kinetic analysis of NbWO electrode. a CV curves at various scan rates from 1 to $5 \mathrm{mV} \mathrm{s} \mathrm{s}^{-1}$. b Determination of the $b$-values at various potential. Contribution of the capacitive behavior at $5 \mathrm{mV} \mathrm{s}^{-1}$ (c) and 1 to $5 \mathrm{mV} \mathrm{s}^{-1}$ (d)

improved gradually with increasing scan rates. The value of $76.8 \%$ obtained at $1 \mathrm{mV} \mathrm{s}^{-1}$ finally reaches the value of $91.2 \%$ at $5 \mathrm{mV} \mathrm{s}^{-1}$.

Considering its high rate capability, long cycle stability, NbWO represents a superb negative electrode material for ultra-stable ALICs. Figure 5a shows the ALIC's configuration based on the NbWO negative electrode and oxygen-enriched crumpled graphene (OECG) positive electrode. Considering the electrochemical performance of OECG as shown in Figs. S5 and S6, the maximum work voltage of ALIC is forecasted to be $2.2 \mathrm{~V}$ with an optimized mass ratio of $1: 1.1$ (NbWO:OECG). A series of $\mathrm{CV}$ measurements with various voltage windows was conducted to identify the optimum working window (Fig. 5b). With an increase in the voltage to $2.0 \mathrm{~V}$, the response current increased. However, when the ALIC is measured at a higher voltage of 2.1 or even $2.2 \mathrm{~V}$, obvious polarization is observed. Thus, we use an optimum voltage window of $0-2.0 \mathrm{~V}$ to further evaluate the electrochemical performance of ALIC. As shown in Fig. 5c, the GCD curves for this ALIC at various current densities from 0.15 to $20 \mathrm{~A}$ $\mathrm{g}^{-1}$ exhibit symmetric quasi-triangular shapes, demonstrating a combination of different charge storage mechanisms of ECs and batteries. Specially, the GCD curves of the NbWO negative electrode and OECG positive electrode vs. $\mathrm{Ag} / \mathrm{AgCl}$ reference electrode, along with the voltage profile of the ALIC are shown in Fig. S7. During the electrochemical reaction of positive electrode, there is a linear increase/decrease in potential with respect to time, which suggests the good absorption/ desorption of $\mathrm{Ac}^{-}$and subsequent double layer formation across the OECG electrode/electrolyte interface. The NbWO negative electrode has obvious slops in the potential region of -1.3 to $0 \mathrm{~V}$. Furthermore, it can also be observed that the $\mathrm{OECG} / \mathrm{NbWO}$ exhibits a quasi-triangular voltage profile from 0 to $2 \mathrm{~V}$, resulting from the difference between the positive electrode and the negative electrode. The ultra-long cycling stability of the ALIC (Fig. 5d) was demonstrated at a current density of $2 \mathrm{~A} \mathrm{~g}^{-1}$, with a capacity retention of almost $100 \%$ up to 50,000 cycles, which is one of the longest cycling 
(a)

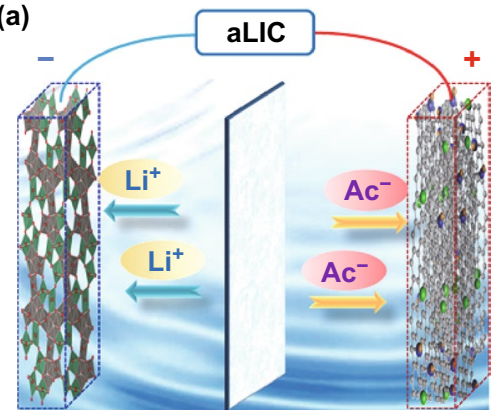

(b) 1

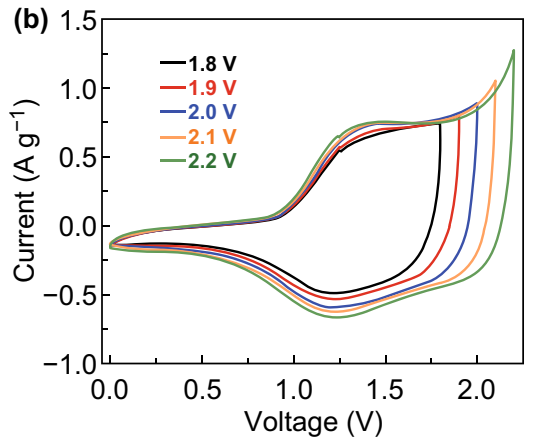

(c)

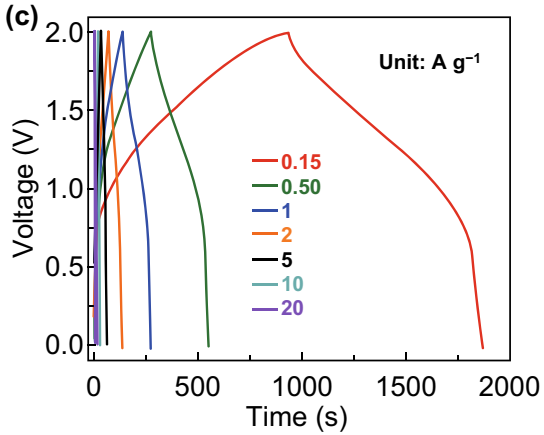

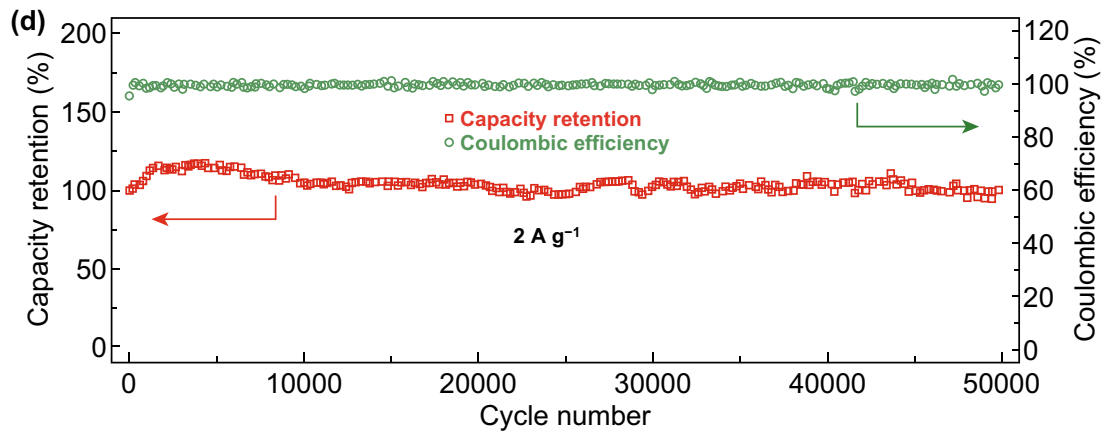

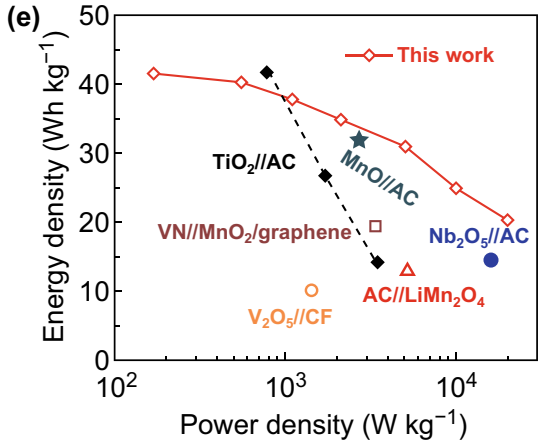

Fig. 5 Electrochemical evaluation of (+)OECG//NbWO(-) ALIC. a The diagrammatic sketch of electrochemical reaction mechanism. b CV curves of the ALICs collected at different voltage windows at fixed $5 \mathrm{mV} \mathrm{s}^{-1}$. c GCD curves at different current density between 0 and $2 \mathrm{~V}$. d Capacity retention and Coulombic efficiency for 50,000 cycles at a current density of $2 \mathrm{~A} \mathrm{~g} \mathrm{~g}^{-1}$. e Ragone plots for the OECG//NbWO ALICs and compared with other aqueous and non-aqueous LICs reported in the studies

performances for aqueous [48-50], and non-aqueous LICs [41, 45, 51-53] (see Table S3 for detail). In addition, the Ragone plot (Fig. 5e) demonstrates superior power and energy characteristics of the designed ALIC. A high energy density of $41.9 \mathrm{Wh} \mathrm{kg}^{-1}$ (based on the total active mass of both electrodes; similarly hereinafter) is achieved at the power density of $170.6 \mathrm{~W} \mathrm{~kg}^{-1}$. Even at a high power density of $20 \mathrm{~kW} \mathrm{~kg}^{-1}$, the ALIC still possesses an energy density of $20.2 \mathrm{Wh} \mathrm{kg}^{-1}$. Compared with other reported LICs in aqueous and non-aqueous systems, such as, $\mathrm{AC} / / \mathrm{LiMn}_{2} \mathrm{O}_{4}$ [54], $\mathrm{V}_{2} \mathrm{O}_{5} / / \mathrm{CF}$ [48], VN// $\mathrm{MnO}_{2} /$ graphene [55], $\mathrm{Nb}_{2} \mathrm{O}_{5} / / \mathrm{AC}$ [38], $\mathrm{TiO}_{2} / / \mathrm{AC}$ [56], $\mathrm{MnO} / /$ $\mathrm{AC}$ [57], the OECG//NbWO ALIC device has superior energy and power characteristics. These results revealed that $\mathrm{NbWO}$ material effectively overcome the mismatch of charge storage and sluggish kinetics.

\section{Conclusions}

In summary, we developed a green LiAc-based WiSE with a wide electrochemical stability window of $2.8 \mathrm{~V}$. MD simulations confirmed the nature of LiAc-based WiSE system, where hydrogen bonds of water-water are disrupted and ionic interactions became stronger than dilute solution. Typical non-aqueous anode material of LIBs, $\mathrm{Nb}_{18} \mathrm{~W}_{16} \mathrm{O}_{93}$, shows fully reversible lithium-ion storage in this green WiSE. Due to NbWO's unexceptionable performance in micro-size particles and wide electrochemical window of green LiAc-based WiSE, NbWO-based ALIC delivers high energy/power characters and ultra-stable cyclability. After 50,000 cycles, the capacity retention is up to 
$100 \%$, which is one of the longest cycling performances for hybrid capacitors. Besides, the cost of maintenance and recycling of LiAc-based hybrid capacitors is low. We believe that presented here green fluorine-free WiSE approach can make aqueous lithium-ion hybrid capacitors close to large-scale energy storage.

Acknowledgements Shengyang Dong and Yi Wang contributed equally to this work. This work was supported by the National Natural Science Foundation of China (Nos. U1802256, 51672128, 51802154), the Key Research and Development Program in Jiangsu Province (BE2018122), Jiangsu Specially-Appointed Professors Program, the Fundamental Research Funds for the Central Universities (NE2016005), the Startup Foundation for Introducing Talent of NUIST (1441622001004).

Open Access This article is licensed under a Creative Commons Attribution 4.0 International License, which permits use, sharing, adaptation, distribution and reproduction in any medium or format, as long as you give appropriate credit to the original author(s) and the source, provide a link to the Creative Commons licence, and indicate if changes were made. The images or other third party material in this article are included in the article's Creative Commons licence, unless indicated otherwise in a credit line to the material. If material is not included in the article's Creative Commons licence and your intended use is not permitted by statutory regulation or exceeds the permitted use, you will need to obtain permission directly from the copyright holder. To view a copy of this licence, visit http://creativecommons.org/licenses/by/4.0/.

Electronic supplementary material The online version of this article (https://doi.org/10.1007/s40820-020-00508-z) contains supplementary material, which is available to authorized users.

\section{References}

1. P. Fairley, Energy storage: power revolution. Nature 526, S102-S104 (2015). https://doi.org/10.1038/526S102a

2. C.S. Rustomji, Y. Yang, T.K. Kim, J. Mac, Y.J. Kim et al., Liquefied gas electrolytes for electrochemical energy storage devices. Science 365(6345), eaal4263 (2017). https://doi. org/10.1126/science.aal4263

3. Z. Liu, Y. Huang, Y. Huang, Q. Yang, X. Li, Z. Huang, C. Zhi, Voltage issue of aqueous rechargeable metal-ion batteries. Chem. Soc. Rev. 49(1), 180-232 (2020). https://doi. org/10.1039/c9cs00131j

4. H. Xia, Q. Xu, J. Zhang, Recent progress on two-dimensional nanoflake ensembles for energy storage applications. NanoMicro Lett. 10, 66 (2018). https://doi.org/10.1007/s4082 $0-018-0219-\mathrm{z}$

5. X. Zeng, C. Zhan, J. Lu, K. Amine, Stabilization of a high-capacity and high-power nickel-based cathode for
Li-ion batteries. Chem 4(4), 690-704 (2018). https://doi. org/10.1016/j.chempr.2017.12.027

6. Z. Zhao, Z. Hu, R. Jiao, Z. Tang, P. Dong et al., Tailoring multi-layer architectured $\mathrm{FeS}_{2} @ \mathrm{C}$ hybrids for superior sodium-, potassium- and aluminum-ion storage. Energy Storage Mater. 22, 228-234 (2019). https://doi.org/10.1016/j. ensm.2019.01.022

7. Y. Huang, J. Mou, W. Liu, X. Wang, L. Dong, F. Kang, C. $\mathrm{Xu}$, Novel insights into energy storage mechanism of aqueous rechargeable $\mathrm{Zn} / \mathrm{MnO}_{2}$ Batteries with Participation of $\mathrm{Mn}^{2+}$. Nano-Micro Lett. 11, 49 (2019). https://doi.org/10.1007/s4082 0-019-0278-9

8. S. Dong, W. Shin, H. Jiang, X. Wu, Z. Li et al., Ultra-fast $\mathrm{NH}_{4}{ }^{+}$storage: strong $\mathrm{H}$ bonding between $\mathrm{NH}_{4}{ }^{+}$and bilayered $\mathrm{V}_{2} \mathrm{O}_{5}$. Chem 5(6), 1537-1551 (2019). https://doi. org/10.1016/j.chempr.2019.03.009

9. M.R. Lukatskaya, J.I. Feldblyum, D.G. Mackanic, F. Lissel, D.L. Michels, Y. Cui, Z. Bao, Concentrated mixed cation acetate "water-in-salt" solutions as green and low-cost high voltage electrolytes for aqueous batteries. Energy Environ. Sci. 11(10), 2876-2883 (2018). https://doi.org/10.1039/ c8ee00833g

10. W. Sun, F. Wang, S. Hou, C. Yang, X. Fan et al., Zn/ $\mathrm{MnO}_{2}$ battery chemistry with $\mathrm{H}^{+}$and $\mathrm{Zn}^{2+}$ coinsertion. $\mathrm{J}$. Am. Chem. Soc. 139(29), 9775-9778 (2017). https://doi. org/10.1021/jacs.7b04471

11. M. Salanne, B. Rotenberg, K. Naoi, K. Kaneko, P.L. Taberna et al., Efficient storage mechanisms for building better supercapacitors. Nat. Energy 1, 16070 (2016). https://doi. org/10.1038/nenergy.2016.70

12. H. Shao, Y.-C. Wu, Z. Lin, P.-L. Taberna, P. Simon, Nanoporous carbon for electrochemical capacitive energy storage. Chem. Soc. Rev. 49, 3005-3039 (2020). https://doi. org/10.1039/d0cs00059k

13. M. Xia, J. Nie, Z. Zhang, X. Lu, Z.L. Wang, Suppressing self-discharge of supercapacitors via electrorheological effect of liquid crystals. Nano Energy 47, 43-50 (2018). https://doi.org/10.1016/j.nanoen.2018.02.022

14. M. Li, Q. Zhou, C. Ren, N. Shen, Q. Chen et al., Surfacing amorphous $\mathrm{Ni}-\mathrm{B}$ nanoflakes on $\mathrm{NiCO}_{2} \mathrm{O}_{4}$ nanospheres as multifunctional bridges for promoting lithium storage behaviors. Nanoscale 11(46), 22550-22558 (2019). https:// doi.org/10.1039/c9nr07733b

15. J. Li, N. Shan, L. Wang, Q. Zhou, Y. Yan, M. Li, C. Guo, Surface engineering $\mathrm{Co}-\mathrm{B}$ nanoflakes on $\mathrm{Mn}_{0.33} \mathrm{Co}_{0.67} \mathrm{CO}_{3}$ microspheres as multifunctional bridges towards facilitating $\mathrm{Li}^{+}$storing performance. Ceram. Int. 46(12), 19873-19879 (2020). https://doi.org/10.1016/j.ceramint.2020.05.046

16. A. Manthiram, A reflection on lithium-ion battery cathode chemistry. Nat. Commun. 11(1), 1-9 (2020). https://doi. org/10.1038/s41467-020-15355-0

17. M.R. Palacín, A. de Guibert, Why do batteries fail? Science 351(6273), 1253292 (2016). https://doi.org/10.1126/scien ce. 1253292

18. B. Anothumakkool, S. Wiemers-Meyer, D. Guyomard, M. Winter, T. Brousse, J. Gaubicher, Cascade-type prelithiation 
approach for Li-ion capacitors. Adv. Energy Mater. 9(27), 1900078 (2019). https://doi.org/10.1002/aenm.201900078

19. S. Dong, L. Shen, H. Li, G. Pang, H. Dou, X. Zhang, Flexible sodium-ion pseudocapacitors based on $3 \mathrm{D} \mathrm{Na}_{2} \mathrm{Ti}_{3} \mathrm{O}_{7}$ nanosheet arrays/carbon textiles anodes. Adv. Funct. Mater. 26(21), 3703-3710 (2016). https://doi.org/10.1002/ adfm.201600264

20. J. Wang, S. Dong, B. Ding, Y. Wang, X. Hao et al., Pseudocapacitive materials for electrochemical capacitors: from rational synthesis to capacitance optimization. Natl. Sci. Rev. 4(1), 71-90 (2017). https://doi.org/10.1093/nsr/nww072

21. J.M. Campillo-Robles, X. Artetxe, K. del TesoSánchez, C. Gutiérrez, H. Macicior et al., General hybrid asymmetric capacitor model: validation with a commercial lithium ion capacitor. J. Power Sources 425, 110-120 (2019). https:// doi.org/10.1016/j.jpowsour.2019.03.121

22. J. Ding, W. Hu, E. Paek, D. Mitlin, Review of hybrid ion capacitors: from aqueous to lithium to sodium. Chem. Rev. 118(14), 6457-6498 (2018). https://doi.org/10.1021/acs. chemrev.8b00116

23. E. Adelowo, A.R. Baboukani, O. Okpowe, I. Khakpour, M. Safa, C. Chen, C. Wang, A high-energy aqueous on-chip lithium-ion capacitor based on interdigital 3D carbon microelectrode arrays. J. Power Sources 455, 227987 (2020). https ://doi.org/10.1016/j.jpowsour.2020.227987

24. L. Suo, O. Borodin, T. Gao, M. Olguin, J. Ho et al., "Waterin-salt" electrolyte enables high-voltage aqueous lithium-ion chemistries. Science 350(6263), 938-943 (2015). https://doi. org/10.1126/science.aab1595

25. Y. Yamada, K. Usui, K. Sodeyama, S. Ko, Y. Tateyama, A. Yamada, Hydrate-melt electrolytes for high-energy-density aqueous batteries. Nat. Energy 1(10), 16129 (2016). https:// doi.org/10.1038/nenergy.2016.129

26. Q. Dou, S. Lei, D.-W. Wang, Q. Zhang, D. Xiao et al., Safe and high-rate supercapacitors based on an "acetonitrile/water in salt" hybrid electrolyte. Energy Environ. Sci. 11(11), 3212-3219 (2018). https://doi.org/10.1039/c8ee0 $1040 \mathrm{~d}$

27. L. Suo, D. Oh, Y. Lin, Z. Zhuo, O. Borodin et al., How solid-electrolyte interphase forms in aqueous electrolytes. J. Am. Chem. Soc. 139(51), 18670-18680 (2017). https://doi. org/10.1021/jacs.7b10688

28. R.-S. Kuehnel, D. Reber, C. Battaglia, Perspective-electrochemical stability of water-in-salt electrolytes. J. Electrochem. Soc. 167(7), 7 (2020). https://doi.org/10.1149/1945-7111/ ab7c6f

29. D.P. Leonard, Z. Wei, G. Chen, F. Du, X. Ji, Water-in-salt electrolyte for potassium-ion batteries. ACS Energy Lett. 3(2), 373-374 (2018). https://doi.org/10.1021/acsenergylett.8b000 09

30. J. Han, H. Zhang, A. Varzi, S. Passerini, Fluorine-free waterin-salt electrolyte for green and low-cost aqueous sodium-ion batteries. Chemsuschem 11(21), 3704-3707 (2018). https:// doi.org/10.1002/cssc. 201801930

31. J.J. Holoubek, H. Jiang, D. Leonard, Y. Qi, G.C. Bustamante, $\mathrm{X}$. Ji, Amorphous titanic acid electrode: its electrochemical storage of ammonium in a new water-in-salt electrolyte. Chem. Commun. 54(70), 9805-9808 (2018). https://doi.org/10.1039/ c8cc04713h

32. K.J. Griffith, K.M. Wiaderek, G. Cibin, L.E. Marbella, C.P. Grey, Niobium tungsten oxides for high-rate lithium-ion energy storage. Nature 559(7715), 556-563 (2018). https:// doi.org/10.1038/s41586-018-0347-0

33. G. Tan, J. Zheng, F. Pan, Molecular dynamics study on the microstructure of $\mathrm{CH}_{3} \mathrm{COOLi}$ solutions with different concentrations. Funct. Mater. Lett. 11(4), 1850075 (2018). https ://doi.org/10.1142/s1793604718500753

34. J. Zheng, S. Chen, W. Zhao, J. Song, M.H. Engelhard, J.-G. Zhang, Extremely stable sodium metal batteries enabled by localized high-concentration electrolytes. ACS Energy Lett. 3(2), 315-321 (2018). https://doi.org/10.1021/acsenergyl ett.7b01213

35. X. Wang, A.Y. Mehandzhiyski, B. Arstad, K.L. Van Aken, T.S. Mathis et al., Selective charging behavior in an ionic mixture electrolyte-supercapacitor system for higher energy and power. J. Am. Chem. Soc. 139(51), 18681-18687 (2017). https://doi.org/10.1021/jacs.7b10693

36. W. Ye, H. Yu, X. Cheng, H. Zhu, R. Zheng et al., Highly efficient lithium container based on non-wadsley-roth structure $\mathrm{Nb}_{18} \mathrm{~W}_{16} \mathrm{O}_{93}$ nanowires for electrochemical energy storage. Electrochim. Acta 292, 331-338 (2018). https://doi. org/10.1016/j.electacta.2018.09.169

37. J. Billaud, F. Bouville, T. Magrini, C. Villevieille, A.R. Studart, Magnetically aligned graphite electrodes for highrate performance Li-ion batteries. Nat. Energy 1, 16097 (2016). https://doi.org/10.1038/nenergy.2016.97

38. H. Wu, G. Chan, J.W. Choi, I. Ryu, Y. Yao et al., Stable cycling of double-walled silicon nanotube battery anodes through solid-electrolyte interphase control. Nat. Nanotechnol. 7, 310-315 (2012). https://doi.org/10.1038/nnano .2012 .35

39. Y. Li, K. Yan, H.-W. Lee, Z. Lu, N. Liu, Y. Cui, Growth of conformal graphene cages on micrometre-sized silicon particles as stable battery anodes. Nat. Energy 1, 15029 (2016). https://doi.org/10.1038/nenergy.2015.29

40. V. Augustyn, J. Come, M.A. Lowe, J.W. Kim, P.-L. Taberna et al., High-rate electrochemical energy storage through $\mathrm{Li}^{+}$ intercalation pseudocapacitance. Nat. Mater. 12, 518-522 (2013). https://doi.org/10.1038/nmat3601

41. E. Lim, C. Jo, H. Kim, M.-H. Kim, Y. Mun et al., Facile synthesis of $\mathrm{Nb}_{2} \mathrm{O}_{5} @$ carbon core-shell nanocrystals with controlled crystalline structure for high-power anodes in hybrid supercapacitors. ACS Nano 9(7), 7497-7505 (2015). https:// doi.org/10.1021/acsnano.5b02601

42. Y. Xiong, J. Qian, Y. Cao, X. Ai, H. Yang, Electrospun $\mathrm{TiO}_{2} / \mathrm{C}$ nanofibers as a high-capacity and cycle-stable anode for sodium-ion batteries. ACS Appl. Mater. Interfaces 8(26), 16684-16689 (2016). https://doi.org/10.1021/acsami.6b03757

43. H. Ye, L. Wang, S. Deng, X. Zeng, K. Nie et al., Amorphous $\mathrm{MoS}_{3}$ infiltrated with carbon nanotubes as an advanced anode material of sodium-ion batteries with large gravimetric, areal, 
and volumetric capacities. Adv. Energy Mater. 7(5), 1601602 (2017). https://doi.org/10.1002/aenm.201601602

44. S.H. Choi, Y.N. Ko, J.-K. Lee, Y.C. Kang, 3D $\mathrm{MoS}_{2}$-graphene microspheres consisting of multiple nanospheres with superior sodium ion storage properties. Adv. Funct. Mater. 25(12), 1780-1788 (2015). https://doi.org/10.1002/adfm.201402428

45. X. Wang, S. Kajiyama, H. Iinuma, E. Hosono, S. Oro et al., Pseudocapacitance of MXene nanosheets for high-power sodium-ion hybrid capacitors. Nat. Commun. 6, 6544 (2015). https://doi.org/10.1038/ncomms7544

46. J. Park, M. Lee, D. Feng, Z. Huang, A.C. Hinckley et al., Stabilization of hexaaminobenzene in a $2 \mathrm{D}$ conductive metal-organic framework for high power sodium storage. J. Am. Chem. Soc. 140(32), 10315-10323 (2018). https://doi. org/10.1021/jacs.8b06020

47. B. Guo, X. Yu, X.-G. Sun, M. Chi, Z.-A. Qiao et al., A longlife lithium-ion battery with a highly porous $\mathrm{TiNb}_{2} \mathrm{O}_{7}$ anode for large-scale electrical energy storage. Energy Environ. Sci. 7(7), 2220-2226 (2014). https://doi.org/10.1039/C4EE00508B

48. L. Li, S. Peng, H.B. Wu, L. Yu, S. Madhavi, X.W. Lou, A flexible quasi-solid-state asymmetric electrochemical capacitor based on hierarchical porous $\mathrm{V}_{2} \mathrm{O}_{5}$ nanosheets on carbon nanofibers. Adv. Energy Mater. 5(17), 1500753 (2015). https ://doi.org/10.1002/aenm.201500753

49. C. Zhou, Y. Zhang, Y. Li, J. Liu, Construction of high-capacitance 3D CoO@polypyrrole nanowire array electrode for aqueous asymmetric supercapacitor. Nano Lett. 13(5), 20782085 (2013). https://doi.org/10.1021/nl400378j

50. W. Chen, C. Xia, H.N. Alshareef, One-step electrodeposited nickel cobalt sulfide nanosheet arrays for high-performance asymmetric supercapacitors. ACS Nano 8(9), 9531-9541 (2014). https://doi.org/10.1021/nn503814y

51. P. Wang, R. Wang, J. Lang, X. Zhang, Z. Chen, X. Yan, Porous niobium nitride as a capacitive anode material for advanced li-ion hybrid capacitors with superior cycling stability. J. Mater. Chem. A 4(25), 9760-9766 (2016). https://doi. org/10.1039/c6ta02971j

52. J.H. Kim, J.-S. Kim, Y.-G. Lim, J.-G. Lee, Y.-J. Kim, Effect of carbon types on the electrochemical properties of negative electrodes for Li-ion capacitors. J. Power Sources 196(23), 10490-10495 (2011). https://doi.org/10.1016/j.jpows our.2011.08.081

53. H. Wang, Y. Zhang, H. Ang, Y. Zhang, H.T. Tan et al., A high-energy lithium-ion capacitor by integration of a 3D interconnected titanium carbide nanoparticle chain anode with a pyridine-derived porous nitrogen-doped carbon cathode. Adv. Funct. Mater. 26(18), 3082-3093 (2016). https://doi. org/10.1002/adfm.201505240

54. L. Chen, W. Zhai, L. Chen, D. Li, X. Ma et al., Nanostructured $\mathrm{LiMn}_{2} \mathrm{O}_{4}$ composite as high-rate cathode for high performance aqueous Li-ion hybrid supercapacitors. J. Power Sources 392, 116-122 (2018). https://doi.org/10.1016/j.jpows our.2018.04.103

55. T. Zhai, X. Lu, Y. Ling, M. Yu, G. Wang et al., A new benchmark capacitance for supercapacitor anodes by mixed-valence sulfur-doped $\mathrm{V}_{6} \mathrm{O}_{13-\mathrm{x}}$. Adv. Mater. 26(33), 5869-5875 (2014). https://doi.org/10.1002/adma.201402041

56. H. Kim, M.-Y. Cho, M.-H. Kim, K.-Y. Park, H. Gwon et al., A novel high-energy hybrid supercapacitor with an anatase $\mathrm{TiO}_{2}$-reduced graphene oxide anode and an activated carbon cathode. Adv. Energy Mater. 3(11), 1500-1506 (2013). https ://doi.org/10.1002/aenm.201300467

57. C. Liu, C. Zhang, H. Song, X. Nan, H. Fu, G. Cao, MnO nanoparticles with cationic vacancies and discrepant crystallinity dispersed into porous carbon for Li-ion capacitors. J. Mater. Chem. A 4(9), 3362-3370 (2016). https://doi.org/10.1039/ c5ta10002j 